\title{
Refractory Malignant Solid Neoplasm
}

National Cancer Institute

\section{Source}

National Cancer Institute. Refractory Malignant Solid Neoplasm. NCI Thesaurus. Code C133737.

A malignant solid neoplasm that does not respond to treatment. 